\title{
Breve historización de las revistas digitales de cultura y literatura en Argentina: el caso No Retornable
}

\author{
DIEGO VIGNA Universidad Nacional de Córdoba - CONICET, Argentina \\ ORCID 0000-0002-1353-6408 \\ diegovigna@unc.edu.ar
}

\section{Resumen}

Este artículo busca caracterizar la aparición y evolución de la revista No Retornable, nacida en 2005 , como caso representativo de las publicaciones colectivas digitales dedicadas a la literatura y la cultura que fueron poblando el campo de producción argentino desde la primera década del siglo. El contexto de la poscrisis 2001 en Argentina marcó, en simultáneo, la desaparición de revistas culturales paradigmáticas y la aparición de otras digitales que consolidaron las mutaciones técnicas y simbólicas hoy tan discutidas. La hipótesis es que, junto a otras revistas y blogs pioneros, No Retornable marcó el pulso de la expansión digital de publicaciones periódicas (que hoy utilizan al blog como formato de publicación) operando como espacio transicional entre las lógicas de producción, edición y publicación de las revistas impresas y las formas dinámicas, tanto de producción como de circulación y recepción, que impusieron los formatos web. No Retornable buscó un nuevo modo de visibilizar autores y de renovar la producción crítica, pero también llegó a representar los obstáculos que encuentran los objetos digitales para resistir al tiempo: este trabajo propone un análisis de caso que ilustra la tensión entre el ciclo vital de las revistas y el problema del archivo como signo de época.
Palabras clave: revistas literarias y culturales / formatos de publicación web / campo literario argentino / archivo

\section{Brief historization of the digital magazines of culture and literature in Argentina: the No Retornable case}

Abstract

This article seeks to characterize the appearance and evolution of No Retornable magazine, born in 2005, as a representative case of the collective digital publications dedicated to literature and culture that began to populate the Argentine production field in the first decade of the century. The context of the post 2001 crisis in Argentina marked the disappearance of paradigmatic cultural magazines and, at the same time, the appearance of other digital ones that consolidated those technical and symbolic mutations that are widely discussed nowadays. The hypothesis is that, along with other pioneering magazines and blogs, No Retornable marked the pulse of the digital expansion of periodical publications (which now use the blog as a publication format) operating as a transitional space between the logics of production, edition, and publication of printed magazines and the dynamic forms of production,

Recibido: 4/6/2021. Aceptado: 23/8/2021

Para citar este artículo: Vigna, D. (2021). Breve historización de las revistas digitales de cultura y literatura en Argentina: el caso No Retornable. El taco en la brea, (14) (junio-noviembre). Santa Fe, Argentina:

UNL. e0056 DOI: 10.14409/tb.2021.14.e0046 
circulation, and reception brought about by web formats. No Retornable sought a new way to make authors visible and to renew critical production, but it also came to represent the obstacles that digital objects face in resisting time: this work proposes a case analysis that illustrates the tension between the life cycle of magazines and the problem of the archive as a sign of the period.

Key words: literary and cultural magazines / web publishing formats / Argentine literary field / archive

\section{Introducción}

Dos compilaciones dieron cuenta, en los últimos años, de las aristas que sostienen este trabajo. Por un lado, el dossier que en 2012 publicó la revista El Matadero sobre revistas literarias y culturales de Argentina.' Lo valioso del dossier es que se organiza a partir del quiebre que significó, con el cambio de siglo como testigo, la desaparición de revistas paradigmáticas en papel como Punto de vista, El ojo mocho o Diario de poesía, medios centrales para la difusión y el debate literario e intelectual (teórico), y la aparición en ese mismo periodo de otras revistas, nacidas digitales, que marcaron el pulso de la poscrisis de 2001 en Argentina, y que tradujeron las mutaciones técnicas y simbólicas hoy tan analizadas.

Por otro lado, recupero un dossier de la revista Letral (2018) dedicado a celebrar las dos décadas del nacimiento del blog. ${ }^{2}$ También parte de una perspectiva literaria pero anclada al trabajo de escritores españoles, con enfoque en los efectos del blog en la evolución de los géneros (la esfera productiva) y los modos de recepción. Es relevante el contraste entre dossieres porque introduce la problemática que me incumbe: el primer ejemplo propone un anclaje histórico y cultural de la aparición de las revistas digitales en Argentina, con la referencia de sus principales antecedentes y condiciones de aparición, y el segundo alude a la dimensión temporal desde una perspectiva literaria y sociotécnica, esto es, el momento en que un formato novedoso y disruptivo multiplicaba su presencia a través de los «blogs de autor» (Vigna, 2014). En el dossier español se recupera el éxito del blog en su apropiación creativa, al que se considera todavía en expansión (Escandell, 2018), pero eso no parece homologable al funcionamiento del campo literario argentino, al menos en términos de blogs personales: sí lo es en el marco de las publicaciones periódicas. Mientras el dossier español pivotea desde el formato para explicar la matriz interactiva e hipermedial de la época, que tuvo su auge en Argentina a partir de 2003, llamativamente (o no) las dos revistas digitales de cultura y literatura que reconozco en cierto modo inaugurales en el campo literario argentino, por «sellar» un modo de visibilizar autores y de renovar la crítica de obra, nacieron como sitios 1.o: articuladas con la efervescencia de los blogs personales y colectivos, pero con evidentes rasgos transicionales, protocolos novedosos para el consumo cultural y a la vez atentas a la herencia de revistas impresas.

Las revistas son El Interpretador (EI), fundada en 2003 y dirigida por Juan D. Incardona, y No Retornable (NR), que nació en 2005 y fue dirigida por Sol Echevarría. Me dedicaré a No Retornable para destacar un primer eslabón de esta breve reconstrucción de época. El objetivo del trabajo es, entonces, caracterizar la aparición y evolución de $N R$ como caso representativo de las publicaciones colectivas digitales dedicadas a la literatura y la producción cultural que fueron poblando el campo argentino, desde una actualidad que recoge tantas revistas, y tan atomizadas, que cuesta conocerlas y relevarlas. ${ }^{3}$

La pregunta que guía el recorrido es la siguiente: ¿cómo fue la aparición de $N R$, y de qué modo se insertó en el campo literario e intelectual de la época? Y luego: ¿qué rasgos pueden observarse 
en $N R$ respecto de su estructura, dinámica de publicación y línea editorial, según su condición pionera de revista nacida digital? Mi hipótesis es que, a pesar de que el nacimiento de NR (2005) se produjo en pleno apogeo de la apropiación del blog por parte de escritores, artistas, formaciones culturales y periodistas (de hecho, nació como un blog, para después mutar), la revista, al igual que EI, sentó un modelo de la expansión digital de publicaciones periódicas (que hoy utilizan casi siempre al blog como formato de publicación) operando, ambas, como espacios transicionales entre las lógicas de producción, edición y publicación de las revistas impresas (que no desaparecieron, pero sí comenzaron a perder terreno por razones de costos y velocidades de difusión y visibilidad) y las formas dinámicas, tanto de producción como de circulación y recepción, que impusieron los formatos web.

Para comprender esa transición se debe dar cuenta de los factores que la modelaron: una industria editorial en contracción, que había consolidado una tendencia a la concentración y polarización agudizada en los 90 (Botto, 2006, 2011); un impacto profundo de la crisis social, política y económica que vivió el país desde fines desde 2002, con la disolución de muchas responsabilidades institucionales y, por ende, un reflejo de supervivencia de distintas modulaciones sociales y culturales que debieron regenerar estrategias de reunión, producción y consumo; y la popularización global, por último, de las tecnologías digitales en red, que en medio de tal precariedad comenzaron a ofrecer herramientas desconocidas al campo de producción cultural, y amables para cualquier proyecto independiente y falto de recursos. $N R$ fue una revista virtual desde sus orígenes en 2005, contemporánea de otras pioneras (EI -2003-, Los asesinos tímidos -2007; en adelante LAT-) así como de blogs colectivos dedicados a la crítica (Los trabajos prácticos —1998—; Nación Apache —2006-) y personales (Linkillo —2003—, de Daniel Link; Wimbledon -2003 - de Guillermo Piro) que oficiaban como nuevos refugios de literatura, ensayo y reflexión, de actualización casi diaria. Tanto NR como EI (como también Linkillo, en otro tenor) comenzaron a circular por ámbitos académicos porque de allí surgieron sus fundadores, y representaron, como dijo Mariano Vilar (2015:126), un horizonte inmediato para los recién llegados al campo literario que mostraron sus obras en la primera década del siglo. En el caso de $N R$, se puede dividir su existencia en dos periodos. Primero funcionó como un blog de actualizaciones irregulares, y luego, desde 2008, como un sitio web «convencional», reproductor de una estructura de números definidos, con dossieres programados y artículos por encargo.

Pero antes de repasar la vida de la revista, y de articular antecedentes y conceptos que enmarcan su abordaje, quiero poner énfasis en la complejidad que surge del contexto de aparición de estos artefactos culturales, con tantas mutaciones en tan poco tiempo. No se puede desligar a $N R$ de la herencia impresa, y frente a la necesidad de establecer un método para el análisis de estas publicaciones se destaca el problema de la temporalidad. Como sintetizó Vilar (2014) en la línea de los estudios sobre este objeto (Gramuglio, 1983; Sarlo, 1992; Gilman, 1999; Patiño, 2008; Weinberg, 2011), el problema central de toda revista cultural es su capacidad de intervención en la esfera pública, y por lo tanto la construcción de su temporalidad. Para lograr esto, Vilar resume lo que cualquier intervención necesita: primero, que exista un campo donde intervenir y, segundo, que los actores de ese campo reconozcan a la revista que pretende intervenir (2014).

Si atendemos a la masificación de los medios digitales y la injerencia que han tenido en la producción literaria (al menos en Argentina), los elementos citados flaquean: el éxito de la cultura conectiva (Van Dijck, 2016), basado en la expansión de internet como estructura hegemónica 
de medios, parece haber propiciado una implosión del campo literario si se lo piensa desde la complementariedad de soportes (su vínculo con lo anterior). Las relaciones que supieron analizarse desde, por ejemplo, las luchas históricas de distinción y legitimación dentro de un campo de producción específico (con Bourdieu —2002-a la cabeza), o posiciones más culturalistas que analizaron el impacto de la comunicación masiva en la producción cultural y las experiencias de los actores involucrados (Williams, 1994), se ven trastocadas en las temporalidades del consumo digital que rompió la dinámica corto-largoplacista en los procesos y demandas que definen estrategias de visibilidad o búsqueda de prestigio, así como reformuló las experiencias compartidas: autores, lectores, editores, sellos editoriales, librerías, medios de difusión, periodistas, publicaciones periódicas, han debido adecuarse a las velocidades de los flujos de datos, y ni los objetos impresos en su consideración histórica (expresiones mercantiles de la relación entre agentes, instituciones y consumidores) hoy pueden escapar a las exigencias de la convergencia digital. Este trabajo se inscribe en una actualidad que afecta notablemente a las publicaciones periódicas. Y hasta podría arriesgar que la misma industria del libro, absorbida por los modos de producción y obsolescencia de los circuitos de comercialización de corto plazo, depende cada vez más de una visibilidad intensa pero efímera, solo para pasar a otra novedad, lo que ha acercado al libro a esa dinámica ajena de actualización permanente.

\section{Herencia de revistas impresas: de la crítica al cambio de siglo}

Muchos autores se han dedicado a analizar el protagonismo de revistas y suplementos literarios y culturales en la constitución del campo literario argentino desde comienzos de siglo XX. Entre ellos, Roxana Patiño (2006) ofreció una sintética línea de proyectos que puede ilustrar mojones de tal influencia. De Martín Fierro (1924-1927) a Sur (1931-1979); de Contorno (1957-1959) a Punto de vista (1978); o del suplemento literario del diario La Nación, baluarte de la cultura liberal, y de Clarín (hoy edita la revista de cultura Ñ), representante en su momento de un nacionalismo cultural moderado, hasta el suplemento Radar de Página 12 (vocero del progresismo cultural durante los 80 y 9o), tal cadena de acciones y reacciones, propuestas y respuestas dio forma y organización al territorio cultural e intelectual, además de que, como escribieron Altamirano y Sarlo (1983), se posicionaron como espacios de producción y reproducción estética tanto para criticar y legitimar obras como para experimentar nuevas formas teóricas de abordar las artes y la literatura nacional.

La misma Sarlo encabezó trabajos que impulsaron, desde la revista Punto de vista, perspectivas teóricas que hacia fines del siglo XX canonizaron una forma de pensar y abordar el campo de acción de estas publicaciones. Pero uno de los principales aportes de esa traducción local de las teorías venidas del norte en los años 70 y 80 fue, justamente, el de ayudar a concebir la literatura no como territorio textual aislado, sino en su dimensión institucional en pos de ser pensada como verdadero espacio político, articulador de discursos, prácticas e instituciones (Delgado, 2014:13).

Estos antecedentes (publicaciones que actualizaron formas de posicionamiento discursivo según el contexto nacional) permitieron que muchos trabajos posteriores hayan intentado definir métodos de lectura y análisis de publicaciones periódicas que incluyan las razones de origen de un medio (la citada Gramuglio; Pita González y Grillo —2015—; Artundo -2010-, Delgado —2014 -, Badenes -2016 -, entre otros). Eso es lo que aquí pretendo con NR. Tal 
enfoque toma relieve en el hecho de que el nacimiento de las publicaciones periódicas que leyeron a las revistas impresas, estructurantes de una mirada articuladora, representa un eslabón en esa cadena evolutiva (Bernini, 2015). NR, como EI, como Planta o Luthor algunos años después, son revistas digitales que se constituyeron asociadas al campo académico (estudiantes de letras que asistían a las mismas clases, con inquietudes similares) pero cuestionadoras de las formas establecidas desde fines del siglo anterior, y que por tanto son deudoras de ese mismo linaje teórico, en Argentina profundizado en la tensión entre estructuralismo, posestructuralismo y estudios culturales, así como también del devenir específico del campo editorial tensado en la confrontación de intereses ideológicos y políticos desde la producción estética (propio de las décadas de los 50, 60 y 70), o en la batalla academia versus mercado que varias revistas utilizaron para obtener visibilidad (décadas del 80 y 90). Procesos que exceden al nacimiento de proyectos aislados y que, sin perder de vista la independencia de las revistas, dan cuenta de la evolución de un periodo histórico según las búsquedas, intenciones y propuestas de relevamiento y mostración de lo producido. Es decir, las razones de un campo de producción cultural y artística que se sostiene en líneas reconocibles más allá del soporte y las formas de circulación.

Por eso es importante destacar la herencia impresa, y teórica, que consideraba a las revistas como redes de la crítica (Altamirano y Sarlo, 1983:96), donde a su vez germinaban grupos que alimentaban el campo cultural al establecer modalidades distintas de lectura, al decir de Patiño (2008). De allí también brotan pensamientos que, como el de Vilar o Diego Peller (2015), siguen preguntándose por la capacidad de las revistas de intervenir en el presente, visibilizando discusiones, oficiando como antenas de lo nuevo (Patiño, 2006) o dando nervio al espacio público a partir de nuevas propuestas estéticas (Weimberg, 2011). El punto común a todas las menciones es el de crear sentido (y realidad) sobre el sentido de las obras. Esa pareciera ser la traducción de lo que las revistas impresas consolidaron como una función de cuestionamiento de cánones literarios, culturales e ideológicos (Crespo, 2010), que construía nuevas tendencias, y que hoy encontramos reformulado en la experiencia digital. La pregunta que surge es: si las revistas impresas supieron leer las distintas etapas de la producción literaria y el pensamiento argentino, en tanto textos colectivos $^{4}$ (Olmos, 2003), ¿cómo pensar la continuidad de ese "programa» en la segunda década del nuevo siglo? Esta pregunta no tiene respuesta certera, pero sí el intento remite a describir cómo surgieron las revistas digitales en los años inaugurales de la Word Wide Web, antes de lo que fue la fiebre de las redes sociales online que terminó por desbaratar el panorama inicial.

Antes del cambio de siglo ya se hacía hincapié en un contexto de transición dentro del universo de las revistas, que podría pensarse como la introducción a lo que enuncié como hipótesis. Transición que, como afirma Patiño (1997), se materializó en las formas de abordar los debates culturales y artísticos de los 80 y 9o, sobre todo por la adecuación (o búsqueda de supervivencia) que hubo en las políticas editoriales que empezaron a interrogarse, primero, por los modos de consumo cultural que marcaron al fin de siglo, y luego por el consecuente lugar de la literatura y las artes en los medios. Hernaiz (2012) trabajó específicamente esto, al pensar el movimiento que empezó a vislumbrarse en las revistas de «ensanchamiento de lo literario»; esto es, una búsqueda de ampliación del campo (que buscó nuevos objetos de crítica y de creación y mezcla, en general lejanos al campo académico y más cerca de la industria del entretenimiento: nuevos productos para vincular con los géneros literarios) que significó, en paralelo, un abandono de la potencia ideológica reconocible en la función comunicativa de las revistas, sobre todo a partir de los años 
90 (Hernaiz, 2012). El reacomodo de las revistas tuvo, en este sentido, un intento de cuestionar los perfiles académicos para que las obras literarias llegaran a espacios más amplios a los que siempre habían llegado (Aguirre, en Hernaiz, 2007). Aquí se inscribe el objeto revista digital, montado sobre una respuesta al (ante)último gran caos político y social en Argentina.

Tal respuesta pudo encauzarse en el boom de sociabilidad (Vanoli, 2015) que tradujo esa ampliación del campo en el incipiente terreno virtual vehiculizado por sitios web y blogs. Si la producción literaria, y los objetivos de intervención y crítica de las revistas, habían empujado hacia el espacio público nuevos objetos «analizables», una consecuencia esperable fue que las primeras revistas digitales dedicadas a tal fin nacieron de los círculos académicos (el círculo, en realidad: la carrera de letras) pero con la intención de comenzar a mostrar cómo la teoría literaria y los estudios de arte debían adecuarse a la época. El quiebre que propiciaron las tecnologías digitales es el de la circulación (e interlocución) del objeto artístico y del abanico de producción y recepción crítica resultante, que acentuó la reformulación de la figura del intelectual iniciada en la espectacularización de los 9o, ahora más atado a las agendas mediáticas diversificadas en la hipermedialidad.

\section{Aparición de blogs y revistas digitales: del cambio de siglo a la visibilidad y circulación}

Como dije, la coyuntura a partir de 2002 en Argentina (derrumbe económico, devaluación, mercado editorial deficitario, popularización de internet, proyectos editoriales atomizados y en busca de alternativas de supervivencia) se caracterizó por la proliferación de métodos informales de circulación y promoción de autores y obras, algo que se produjo en simultáneo a la reproducción de nuevos hábitos de lectura, más fragmentarios (Echevarría, 2009). En definitiva, lo que se produjo en simultáneo fue una crisis estructural y la irrupción de tecnologías digitales en red.

Como resumieron Echevarría (2009) y Pron (2009) en dos textos contemporáneos al periodo, en esos años muchas publicaciones impresas se discontinuaron e informalizaron, y se acentuó una atomización en pequeños grupos editoriales que se multiplicaron en el medio digital. Hubo un aumento de textos disponibles, y por ende una proliferación de estéticas que no eran visibles por tal falta de cauce editorial. Esto es lo que explicó, para Echevarría, la aparición de comunidades literarias y artísticas desfasadas de los cánones editoriales de gran envergadura, que tensaron aún más los umbrales entre lo culto y lo masivo del consumo. Se multiplicaron los grupos y formaciones, que se apropiaron de lógicas de intervención comunitaria inauguradas por los formatos web no solo para el terreno virtual, sino también para replicarlas en la presencialidad, en las rutinas de reunión y difusión de obras (grupos de lectura, festivales de lecturas públicas, gestión de centros culturales, ferias de libros). ${ }^{5}$ La explosión de blogs personales y de revistas es la materialización de lo anterior: años de temas, problemáticas y estéticas que confluyeron en una suerte de discurso compartido, cuando publicar en papel se había tornado difícil para proyectos de pequeña envergadura. Se produjo así una reformulación de la relación literatura-mercado, bien descrita por Drucaroff (2007), porque las publicaciones con fines comerciales quedaron prácticamente restringidas a los conglomerados de sellos editoriales.

Las revistas nacidas en el nuevo siglo, impresas y digitales, buscaron visibilidad a partir de contenidos muchas veces ignorados por las agendas editoriales y los medios de distribución masiva. Esto inauguró condiciones de producción y circulación particulares: para Daniel Link, 
por ejemplo, pionero en el mantenimiento de un espacio virtual (Linkillo), ${ }^{6}$ la primera década del siglo propició «micropolíticas intelectuales» que (re)generaron polémicas y discusiones, sobre todo con relación a lo que se producía y reproducía en internet. A su vez, el debate por la aparición de nuevas herramientas de registro y preservación (archivos digitales) empezó a tomar relieve ${ }^{7}$ junto con las formas de publicación en red, las posibilidad de intervención en el ciberespacio, y el impacto de esas condiciones en los procesos de escritura y lectura (Link, 2011).

Comparto, por un lado, el reconocimiento de un ethos epocal vinculado a la irrupción de las tecnologías digitales que, según Wortman, implicó movimientos en los valores e imaginarios propios de la vida cotidiana, nuevas relaciones con los objetos culturales, nuevas sensibilidades y, por ende, nuevas prácticas y construcciones de los espacios sociales (2009). Por otro, en términos de articulación entre actores y medios, surgió un cambio en el modelo de consumo a partir de proyectos que antes parecían regirse por la premisa de criticar para comprender (e imponer nuevos sentidos a la producción cultural, literaria y artística) y luego complementaron esa construcción de sentido con indagaciones sobre cómo hacer circular artes, escrituras e ideas en una época signada por los flujos de información (Montaldo, 2017).

En trabajos anteriores intenté pasar en limpio los aspectos materiales y formales de las revistas digitales, atendiendo a una significación construida en complemento a los estudios de las revistas impresas. Los aspectos que Delgado (2014), por ejemplo, describió para abordar estas últimas (tipo de papel, cantidad de páginas, periodicidad, lugares de impresión y tiradas, organización de las secciones temáticas o genéricas; presencia de avisos publicitarios, modos de distribución y venta, formas de financiación), en la faceta digital se traducen al reconocimiento de plantillas (cómo se presentan los contenidos) y dinámicas de navegación (qué recorrido propone el diseño web) para dar cuenta de perfiles de lectura, objetivos y sintaxis de cada revista. Así definí tres categorías para las revistas digitales: 1) revistas-blog, que replican el formato y establecen sus publicaciones sin apelar a un número, volumen o dossier, y en las que el diseño responde a la idea de zona donde encontrar los contenidos, con secciones organizadas semánticamente; 2) Revistas por número, volumen o dossier, que replican a las impresas aun apelando al soporte digital, con una periodicidad definida, números organizados por temas, secciones fijas; $y$ 3) revistas mixtas, que anuncian cada actualización de contenidos como si se tratara de un nuevo número, y ofrecen una secuencia organizada, pero cuya estructura responde a la del formato blog (Vigna, 2015).

No Retornable comenzó en la primera categoría pero encontró su tono al periodizarse como revista organizada por números. Esa decisión fue clave para definir una política editorial a partir de las prioridades asignadas a determinados géneros. En este sentido, la construcción identitaria de NR muestra el carácter transicional porque encontró su forma en la réplica de una «organización enciclopédica», y abordando tanto temas de actualidad como desatendidos, pero a su vez no explicitó una línea heredada de pensamiento sino el deseo de hacer visibles escrituras y obras heterogéneas.

\section{No Retornable: recorrido por secciones, dossieres y editoriales}

Divido el recorrido en tres dimensiones de análisis que dan cuenta de las características y modos de funcionamiento de la revista. Como NR ya no se encuentra online, este análisis documental fue posible por la recuperación de los URL caídos, que el servicio Archive.org, a través del motor de 
búsqueda WayBack Machine, archivó según su método de captura y conservación, como también por la realización de entrevistas a la directora y a editores de secciones. Las dimensiones abordadas son: 1) referencias iniciales, periodos de publicación y periodicidad; 2) autodefinición, política editorial y contenidos; 3) fin de ciclo, accesibilidad y resonancia.

\section{Referencias iniciales, periodos de publicación, periodicidad}

No Retornable surgió en 2005 «de manera urgente», según escribió Echevarría en la editorial del número 10: tal urgencia, retórica, apuntaba al deseo de descubrir y hacer visibles narrativas y poéticas que se iban gestando. De modo que en el comienzo, $N R$ buscó ser una revista literaria dedicada a la producción contemporánea, reflejada en los autores convocados: tanto jóvenes en plena actividad, con incipiente presencia en el mercado editorial pero en cierto modo urgidos de visibilidad y difusión que la convivencia de soportes comenzaba a requerir, ${ }^{9}$ como autores reconocidos en la literatura y la academia, convocados para escribir ensayos o reflexiones sobre algún tema particular. ${ }^{10}$

El vínculo con el campo académico no fue menor, sino propiciatorio. Echevarría comenzó con una idea de revista durante el cursado de la licenciatura en letras, donde compartió ideas con otros escritores que ya publicaban e incluso con profesores que mantenían blogs personales (Echevarría, comunicación personal, 19 de julio, 2018)." Junto a Marcelo López, coeditor de NR, forjaron un grupo de estudiantes y artistas que desde la academia hacia la calle buscó indagar en su contexto: primero con textos no académicos, después con una propuesta de lectura más «caprichosa» y activa, con énfasis en los contemporáneos (Echevarría, 2018). Las condiciones de producción eran radicalmente distintas a las actuales: no existían las redes sociales, no se usaban teléfonos móviles para navegar, y los diarios aún se leían en papel. Esto sostiene la afirmación de que el apogeo de los blogs inauguró la articulación entre dos mundos hasta ese momento desconectados, como la literatura y la digitalidad.

El periodo 2005-2008 de NR fue en un blog donde publicaban «cosas sueltas, sin lógica de edición» (Echevarría, 2018). En 2008 la revista logró una «armonía entre forma y contenido», según definieron en el número 10, con una actualización de staffy de diseño gráfico: mayor hincapié en lo visual. Ese cambio desnudó intereses que luego excedieron a lo literario y se tradujeron en coberturas más amplias desde la crítica (además de incorporar a fotógrafos, artistas plásticos y diseñadores). El quiebre formal y editorial llevó a que reunieran todo el primer periodo del blog en lo que llamaron "número cero», suerte de meta-archivo que compiló todos los contenidos y actualizaciones. Esa etapa previa fue para Echevarría el tiempo de "pensar la revista» y su periodicidad, como escribió en el número 1: periodicidad que comenzó atada a las estaciones (cuatro números por año) y fue mermando hasta dos números anuales hacia el final de su recorrido.

Respecto a las referencias de sus pares, $N R$ apareció dos años después que $E I$, dirigida por Incardona. Dentro del universo digital ese fue el diálogo más cercano en los primeros años. Pero en términos conceptuales, Echevarría recuerda a las revistas Otra parte y Punto de vista como experiencias reproductoras de una herencia reconocible en otras como Contorno o Literal. Ese era, para el grupo, el «anclaje imaginario» con lo precedente. Sin embargo, aquí también aparece la singularidad de la época porque, como dijo Echevarría (2018), NR no buscaba la construcción o continuación de un mito sino responder a la necesidad de un proyecto que generara redes de colaboración y lectores. Proponer temas de interés, a través de dossieres, y ofrecer investigaciones 
lo más abarcadoras posibles, con la política de mostrar una heterogeneidad de puntos de vista que modelaran «el burbujeo que era ese presente» (2018). La novedad eran los cruces con otros actores del campo literario. Desde la práctica y también desde la teoría (la composición de los dossieres de «literatura y mercado» - $\mathrm{n}^{\circ} \mathrm{O}-$, «literatura e internet» - $\mathrm{n}^{\circ} 4$-, «La imagen lo es todo» - $\mathrm{n}^{\circ} 3$ - «Ediciones artesanales» $-\mathrm{n}^{\circ} 7$ - lo muestran), fundamentaron la captura del presente con el uso de internet como herramienta central, citando a la figura del internauta como mojón de un tiempo histórico pero destacando la historia de las representaciones sobre el papel de los grupos en la producción de bienes simbólicos (ver Imagen 1). NR fue producto de la puesta

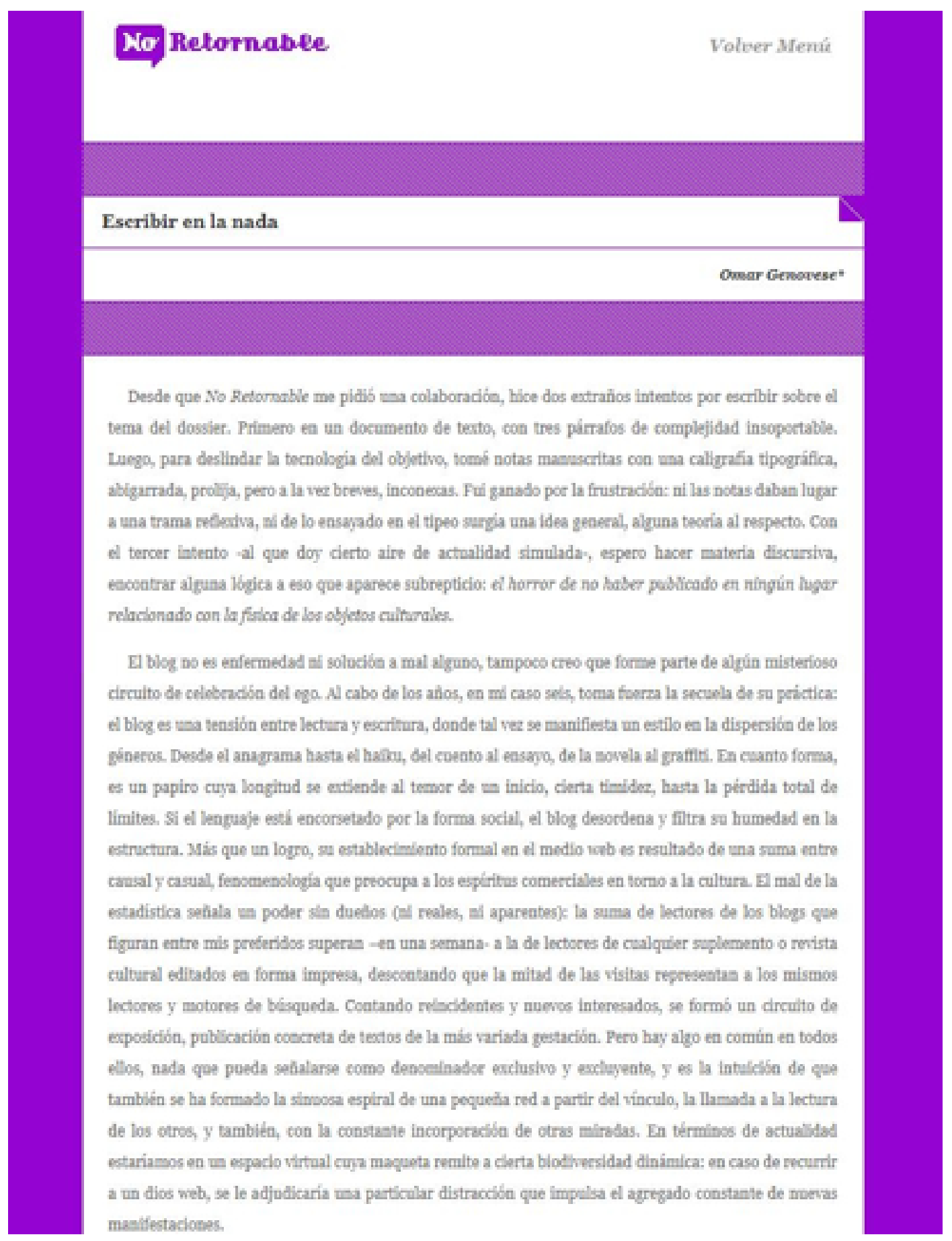

Imagen 1. Para

el dossier del número 4 (Litera tura e Internet), Omar Genovese produce un ensayo sobre el blog como experiencia de lectura y escritura. La reflexión parte de la materialidad para arribar luego al valor creciente de la exposición. En ese dossier, junto a los ensayos, publicaron fragmentos de novelas elaboradas con registros dis cursivos vinculados a la web, como chats. Captura del 28-04-21. https://web. archive.org/web/ 20120106020637/ http://www. no-retornable. com.ar/v4/dossier/ genovese.html 
en acción de los elementos de época: usufructo de un nuevo medio de producción, difusión y circulación de objetos, y puesta en tensión de la ética colectiva, de autopercepción e incidencia en el campo. Una capitalización de afinidades electivas para intervenir el contexto literario.

\section{Autodefinición, política editorial y contenidos: de la literatura a la cultura}

$N R$ hacía de cada editorial un repaso identitario, casi como ejercicio sistemático. La periodicidad estaba pulsada por una pregunta dirigida a la acción y el pensamiento: ¿quiénes somos? Esa pregunta oficiaba como premisa de época, ya que en esos años comenzaron a popularizarse los sitios web que tomaban la expresión «¿Quiénes somos?» como pestaña de presentación, se tratara de empresas o instituciones. Cada sitio web comercial se presentaba con un «quiénes somos», y cada número de $N R$ se apropiaba de la fórmula para una redefinición atada a la temporalidad del espacio en red (Imagen 2).

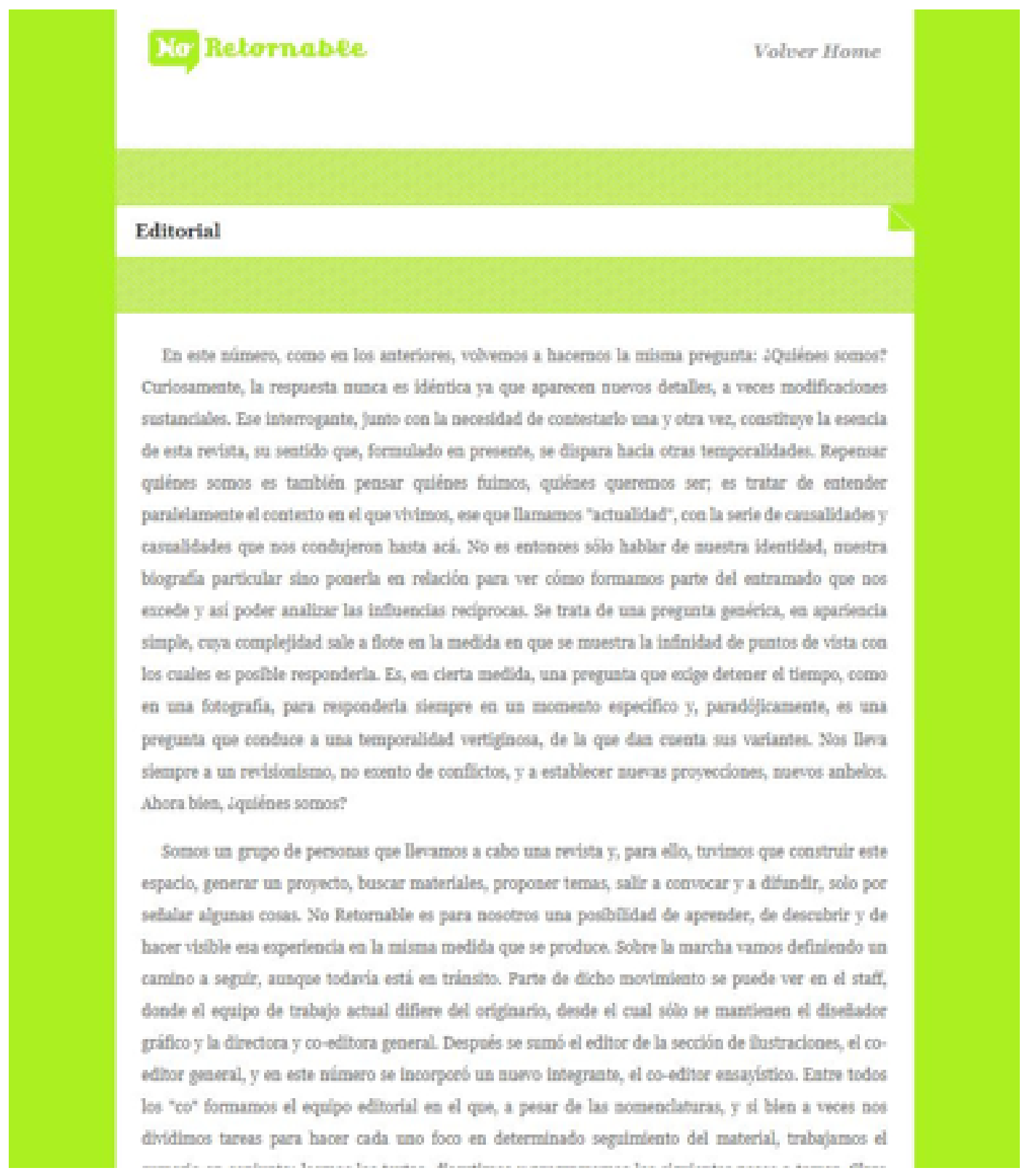

Imagen 2. Fragmento editorial del número 2 (Dossier Malvinas). El recurso se repetía en cada presentación. Captura del 28-04-21. https://web. archive.org/web/ 20160430083613/ http://noretornable.com.ar/ v2/quienes/ 
El primer intento de autodefinición se registra en el número o que reúne la prehistoria de los contenidos publicados. Allí se afirma que la apuesta «riesgosa» de NR era trabajar con la «efímera actualidad»: cómo hacer para que ésta, que por escurridiza se volvía casi inefable, «constituyera un territorio capaz de encontrar una temporalidad propia» (Imagen 3). De modo que el origen de la revista contemplaba la pregunta por la temporalidad digital, sabiendo que el grupo editor se consideraba en la transición de los soportes, un híbrido entre el papel y lo virtual, como se dice en el número 4: ${ }^{12}$ casi la definición de una incerteza (no saber qué era lo digital), aunque existiera la intuición de un nuevo paradigma. De hecho, la pregunta apelaba al problema de la velocidad: cómo trabajar en una "página» de renovación periódica sin caer en el riesgo de lo efímero, donde todo material publicado obligara a la apropiación (no a la devolución) para que las ideas no quedaran «inertes en pantalla». Buscaron adecuar al dinamismo de la web la intención editorial de construir una actualidad nueva: el híbrido de la propuesta recogía del paradigma impreso «el trabajo previo y la planificación», y del digital la «inmediatez y la capacidad de hipervinculación con otros espacios». También creían híbrida la política editorial resultante, por la cantidad y diversidad de colaboradores y las formas de editar las secciones, pero siempre se mantuvo una reflexión vigente sobre la cultura impresa, que fue el germen de la alfabetización: la pregunta sobre cómo proponer un nuevo espacio de «lucha textual» (número 1, 2008) ) $^{13}$ en un espacio donde dejaba de primar el texto. El tiempo permite observar que aunque la web y sus formatos siguen asumiendo un vínculo intrínseco con la cultura letrada, hace veinte años hubo más «contacto» con tal herencia por el incipiente desarrollo de la cultura conectiva e hipermedial.

Con el correr de los números, $N R$ fue expandiendo sus intereses hacia otras artes, registros y abordajes. Desde el número 5, con el dossier dedicado al cine, ya se expresa la «intención de

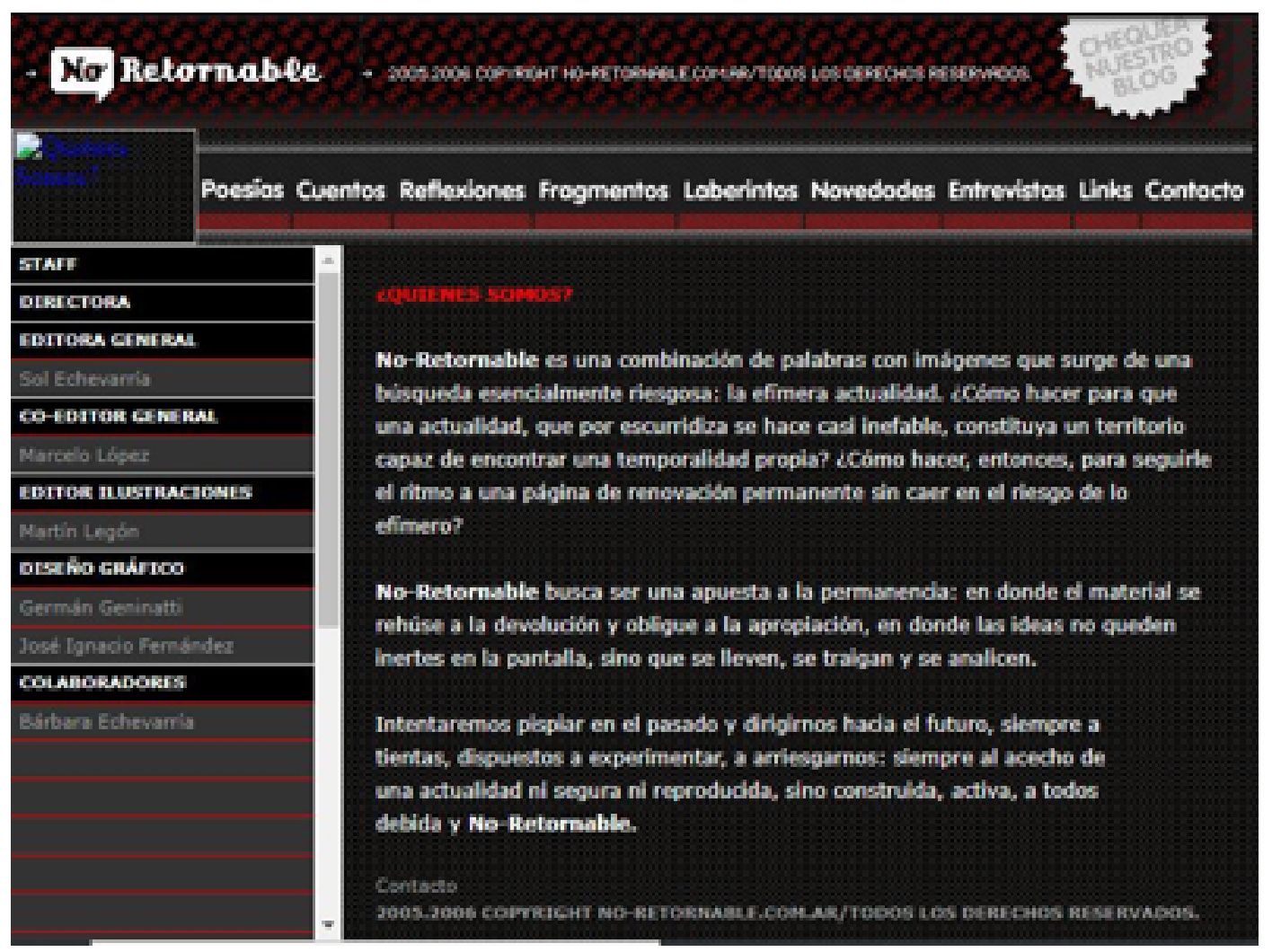

Imagen 3. Primera autodefinición del grupo editorial sobre la revista, en el número 0. En la parte superior, las secciones originales del blog-revista, de 2005 a 2008. Captura del 26-04-21. https://web. archive.org/web/ 20061023021551/ http://www.noretornable.com.ar/ 
captar los movimientos del pensamiento y el arte» que se estaban produciendo. Los números 10 (fotografía), 14 (lo animal), 15 (figuras del mal desde una perspectiva filosófica), 16 (drogas y percepciones culturales) y 17 (periodismo) mostraban lo que en la editorial del número 10 se anunció como el «paso» a una revista cultural..$^{14} \mathrm{El} \mathrm{número} 14$ (un año antes del cierre) establece una definición formal:

No Retornable es una revista cultural independiente que se publica dos veces al año e incluye secciones de crítica literaria, un dossier de ensayos sobre una temática específica que varía de número en número, muestras virtuales de artes plásticas y fotografía, una selección de historietas, y a menudo también cuenta con secciones de poesía, entrevistas, así como de otras cuestiones que nos interpelan. En todos los casos se trata de publicaciones de obras o reflexiones en torno al arte, la cultura y el pensamiento contemporáneo. ${ }^{15}$

Hasta llegar a ese punto, las presentaciones fueron dando cuenta de una caracterización: revista alternativa que no pertenecía a la academia; revista que no era agencia de información; tampoco medio masivo organizado como una empresa. $N R$ se nombró ante todo como revista independiente, y el sostén y desarrollo de tal independencia fue, según se dice en el número 6, la "galaxia virtual». Allí afirman que, sin internet, $N R$ no hubiese podido nacer ni existir.

La naturaleza híbrida y transicional de $N R$ reside en afirmaciones como la anterior frente a la gestión de los contenidos. El trabajo exhaustivo (más «desprolijo», según Echevarría, que en la edición de libros) ${ }^{16}$ era objetivo no negociable en la búsqueda colectiva: la alimentación de un nuevo clima intelectual y artístico podía ser posible en un soporte virtual dedicado a dossieres extensos, textos críticos e investigaciones. Así entra en escena la singularidad editorial de la revista, a partir de las herramientas hipermediales. NR llegó a tener, en los números más extensos, cerca de 100 colaboradores. Las secciones del número o fueron Quiénes somos, Poesías, Cuentos, Reflexiones, Fragmentos, Laberintos, Novedades, Entrevistas, Links, Contacto, y después de 2008 se reorganizaron en Narrativas, Poesía, Reseñas, Artes, Ensayos, con la incorporación de Fotografía, Historietas, Traducciones y textos de dramaturgia. La política definida era de "constante lectura, análisis y difusión de materiales recientes» (Echevarría, 2018), que comenzó con cuentos (inéditos o no), poesía contemporánea (ver Imagen 4) y reseñas y luego incluyó ensayos y dossieres para recuperar y discutir hechos o problemáticas específicas. Los dossieres incluyeron, además de la línea inscripta en las condiciones de producción del vínculo entre escritura, pensamiento y digitalidad, otras coberturas dedicadas a la producción literaria regional (autores brasileños y chilenos, números 11 y 1), efemérides centrales para la construcción identitaria y la política (Guerra de Malvinas, número 2) y una preocupación coyuntural permanente, como el dossier dedicado al conflicto del campo ("Vacas locas», número 1). Más allá de los distintos frentes, la revista siempre hizo hincapié en la ligazón fundamental entre ensayo, crítica y estética, algo que destacaba por su ausencia en las publicaciones de esos años (así lo dicen en el número 4). El problema, para el equipo editorial, no era la escasez de trabajos críticos sino la invisibilización, algo que consideraban capaz de ser combatido desde la «creación de lectores» y sus estrategias comunicativas. El método fue generar propuestas de lectura a partir de nodos críticos, lo que se tradujo en una configuración marcada por una emulsión de premisas académicas (la investigación exhaustiva sobre un tema) y de experimentación formal (dar cuenta de los resultados incorporando cualquier tipo de lenguaje y registro). 


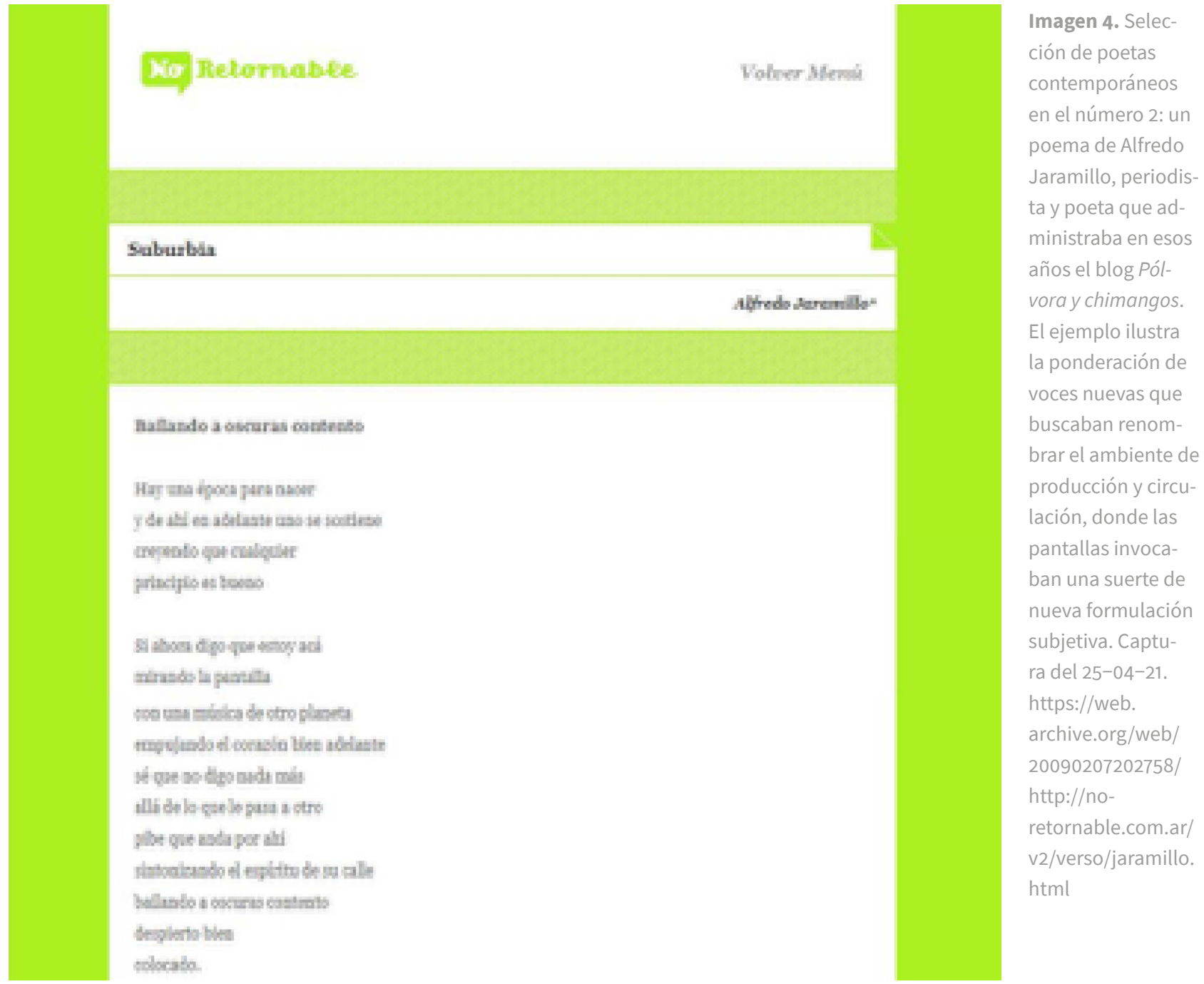

Con todo, el valor analítico del «caso NR» quizás resida en las contradicciones que toda revista tiene con su tiempo mientras intenta dar cuenta de él, es decir, mientras busca construir presente. Quizás la marca distintiva del funcionamiento haya sido la consideración del problema del archivo. La fascinación por los dossieres que destacó Echevarría (2018) da cuenta del perfil del grupo respecto de cómo afrontar las investigaciones por temas. La premisa era incluir en cada número todo el material que surgiera de cada episodio exploratorio: entrevistas (editadas, pero también audios en bruto), charlas, poemas, relatos, cartas (incluso colecciones privadas, como en el dossier Malvinas), traducciones, imágenes, bibliografías: Echevarría lo nombró como un «desenfreno hiperbólico», aquí lo interpreto como una tendencia manifiesta al archivo. Lo digital habilitó elaboraciones documentales antes impensadas para una revista, y propició el trabajo con esa magnitud desbordante de una "primavera de producciones independientes», como escribió Edgardo Scott, editor de narrativa en $N R$ (comunicación personal, 29 de julio, 2020). Se puede ver en la Imagen 5 la amplia tendencia de la producción crítica. Este es un punto central en el intento de historización: la necesidad de reflexionar sobre el vínculo entre revistas digitales y prácticas de archivo, en el contexto de retroalimentación de la escena cultural entre sitios web, blogs, festivales de lectura y libros, nacimiento de grupos y colectivos de artistas (blogs que 
enlazaban con revistas; revistas recomendándose entre sí o dialogando sobre los mismos temas: una charla de espacios virtuales que construyeron un presente hoy casi anacrónico).

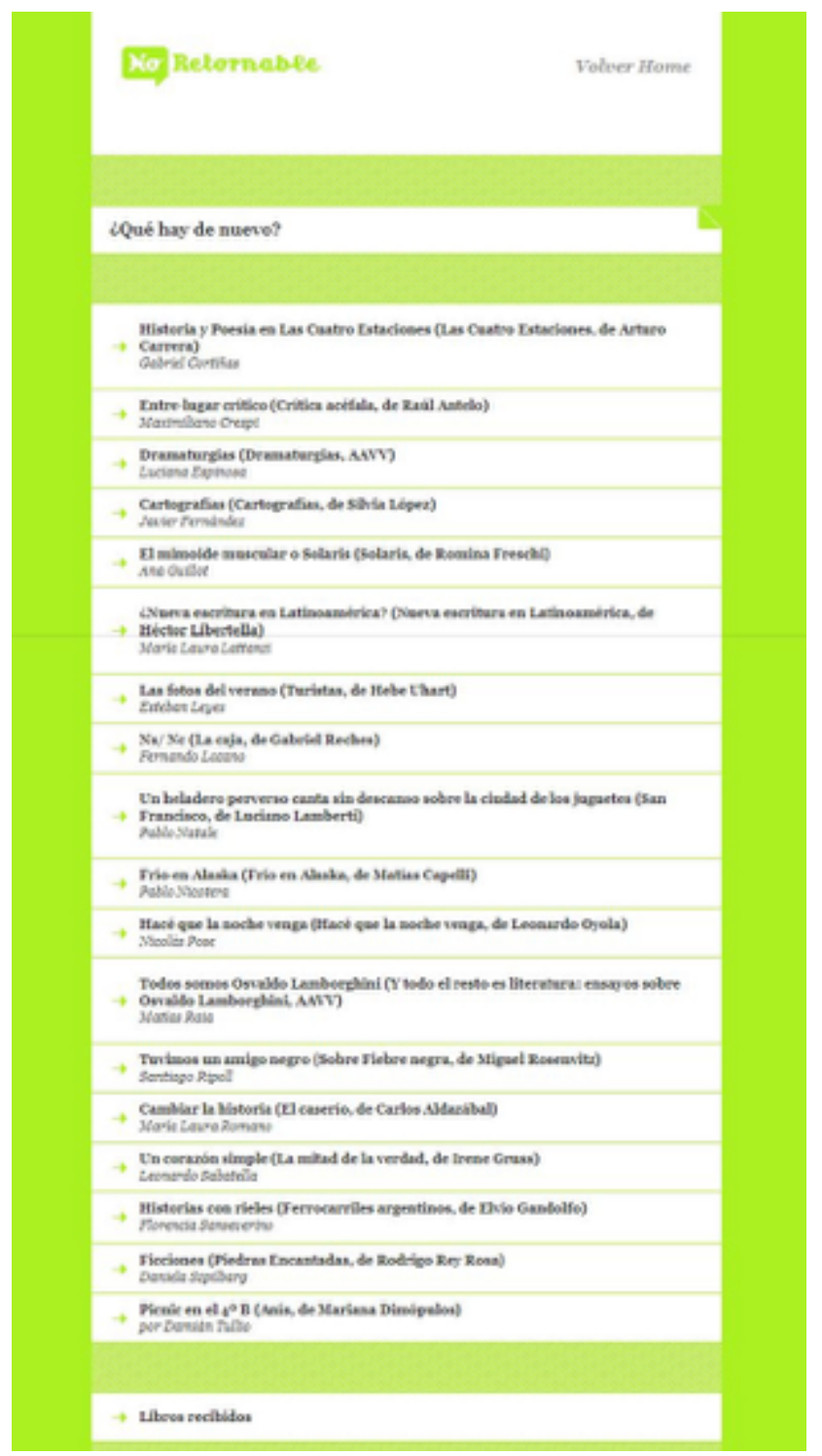

Imagen 5. Sección de reseñas del número 2 que ilustra el perfil heterogéneo: hay reseñas de narradores y poetas jóvenes (Capelli, Oyola, Dimópulos, Aldazábal, Lamberti, Freschi) y consagrados (Antelo, Gandolfo, Uhart, Libertella, Carrera). Puede pensarse que el cruce diverso dependió del mercado editorial, pero los críticos convocados también lo muestran: la mayoría en el inicio de la «vida pública literaria», como Crespi, Szpilbarg, Tullio, Natale, Lozano, etcétera. Captura del 30-04-21. https://web.archive.org/ web/20160428224150/http://no-retornable. com.ar/v2/nuevo/

\section{Fin de ciclo, accesibilidad y resonancia}

Las formas de edición y gestión derivadas de la digitalidad forzaron una reconfiguración de las publicaciones periódicas, a partir de las tensiones entre virtualidad, acceso gratuito y estructuras editoriales. Frente a la pregunta por los costos de edición para los proyectos independientes y sus horizontes de rentabilidad o subsistencia, la aparición de esa potencia alternativa que mezcló en un mismo espacio a autores consagrados con recién llegados adhirió al ethos epocal que amplió estrategias de difusión y volvió a preguntar por los mecanismos de legitimación autoral. En 2013, como posible augurio o simple corolario de un desgaste, la editorial 14 de NR profundizó la reflexión por la temporalidad de las revistas digitales. Allí se preguntaron qué pasaría con las revistas que «no duraran», con el fin de la "conjugación en presente», con el desplazamiento 
temporal en ese formato: dejar de existir en la web era dejar de abonar un host ${ }^{17}$ y no aparecer más en pantalla, a diferencia de un medio impreso que puede dormir su sueño eterno en una hemeroteca o colección privada. La pregunta que se hacían en NR era si, desde lo digital, es posible seguir interrogando el presente a la distancia, recuperando las inquietudes vertidas en el número 1: cómo reacciona un territorio inaccesible que supo construir su propia temporalidad.

$N R$ duró casi una década y logró resonar en el campo literario y artístico del nuevo siglo. Según Echevarría, la revista dejó de actualizarse por varias razones: agotamiento personal, ganas de pasar a otra cosa, y sobre todo la convivencia con el auge de las redes sociales online, que llevó al blog a perder fuerza como medio principal de enlace y de expresión del yo. El otro punto de quiebre fue la mutación de la prensa: «los blogs fueron devorados por tweets, posts y selfies, los diarios fomentaron sus secciones online. Una metástasis digital» (Echevarría, 2018). En ese proceso, muchos proyectos que anidaban en la web «salieron al mundo» en otros formatos. ${ }^{18}$

La reflexión sobre la resonancia parte de la tesis de Hernaiz (2012) acerca de los movimientos de ensanchamiento y diversificación de lo literario, en pos de no sacrificar más espacios de recepción a manos del periodismo y las industrias del entretenimiento. En ese sentido, las revistas digitales pioneras, a diferencia de las que surgieron en la segunda década del siglo, lograron posicionarse como emisarias de la novedad de las velocidades implicadas en la llegada a los lectores. Las redes sociales aniquilaron, luego, la resonancia editorial en pos de la circulación incesante y la viralidad, pero la discusión entre las humanidades y la sociología de cultura sigue abierta: ¿las revistas siguen dando cuenta de la influencia de la producción literaria e intelectual? En la faceta digital, ¿todo se explica por la exaltación de la primera persona? ¿Fueron y son los actores quienes determinaron los procesos, o es responsabilidad del medio?

Diego Peller (2015), estudioso del objeto revista, se interrogó sobre el impacto real de la crítica cultural que visibilizan las revistas argentinas, en términos de afectar una coyuntura. Su lectura de las revistas culturales contempla una tensión constitutiva entre literatura y política a la hora de definir contenidos y diálogos entre autores o grupos, en términos de relevancia, que cualquier urgencia suele inclinar hacia el terreno político por su potencia de actualización. Sin embargo, el mundo digital parece hablar otra lengua, deudora de la anterior pero transmutada: la noción de actualidad que construían las revistas en papel poco tiene que ver con la sobreabundancia de materiales en internet, sobre cualquier tema. Algo que produce, como dijo Vilar, una sensación de «ideas inertes en pantalla» frente a cualquier fantasía intervencionista (2015). Para Vilar, la experiencia de $N R$ no respondió a ninguno de esos extremos. Ni «quedó flotando como base de datos en el ciberespacio», como mero cúmulo de notas, ni buscó un «impacto rabioso» a través de polémicas y gestos esnobs (2015). El problema del archivo incorpora el espacio dinámico en el que diversos estudios pueden dedicarse a pensar qué es y, sobre todo, qué fue una revista digital de literatura y cultura, porque la vorágine actual de medios conectivos obliga a repreguntar: ¿a quiénes interpela una revista digital? ¿A quiénes influencia y, sobre todo, cuándo lo hace?

\section{Temporalidad digital y pulsión de archivo}

Salvo casos reconocidos que contaron con largos periodos de publicación (Punto de vista es un ejemplo, luego continuada parcialmente en una réplica digital, Bazar Americano:;19 o el tándem El escarabajo de oro/El ornitorrinco que salieron desde 1961 hasta 1986), las revistas independientes siempre parecen estar resistiendo, al menos en el contexto argentino. Al mismo tiempo, 
los testimonios de los editores contagian la idea de que los proyectos independientes deben necesariamente nacer, crecer y clausurarse, como el desarrollo de una vida orgánica. De hecho, lo que en una editorial de $N R$ se menciona como «hito cultural» (el hecho de que la revista haya existido ininterrumpidamente por ocho años) es síntoma de la función que cumple una revista: la de irrumpir en un tiempo preciso, con un mandato reconocible, pero siempre perecedero.

En el número 1 de NR se preguntaban cómo hacer para seguirle el ritmo a una página de renovación permanente sin caer en el riesgo de lo efímero. Cómo hacer una apuesta por la permanencia desde el soporte digital sin que tal permanencia sea sinónimo de quietud. Ese ha sido el dilema inaugural de la época, que excede a la producción literaria y artística para llegar a la nueva matriz comunicacional: cómo compatibilizar las bondades de la circulación inmediata y la visibilidad con la inestabilidad de los objetos digitales en red, que viven ante todo de la regeneración, por su condición misma, y del reemplazo (Isoglio y Vigna, 2020). En simultáneo a la existencia de $N R$, Sergio Chejfec mantuvo un blog personal, Parábola anterior, en el que buscaba revertir a consciencia la lógica interactiva del formato para concebirlo en una suerte de «cuasi inmovilidad", desadaptada de la moda. La idea era experimentar con cierta coagulación de los textos en la web: una presencia textual permanente y silenciosa, disponible solo por su condición online (Chejfec, comunicación personal, 13 de abril, 2011).

$N R$ abandonó las pantallas a mediados de 2018, según la anécdota que narré en la nota 17, y su desaparición, contemplada como posibilidad siempre latente, lleva a una pregunta que justifica las tensiones constitutivas: ¿una revista se convierte en archivo cuando se queda «quieta», o es su naturaleza periódica lo que va engordado su potencial archivístico a medida que pasa el tiempo? Sea cual fuere la respuesta, una revista no puede oficiar como archivo si es inaccesible al público, y allí la infraestructura digital (tan material como la analógica) exalta paradojas y desapariciones. NR se dedicó explícitamente a leer y mostrar el presente de los gestos literarios e intelectuales desde sus condiciones de producción, fundando tal énfasis en un diálogo permanente con las formas precedentes. En la apertura del número 14 comienzan a pensar la revista como artefacto posible de ser leído en el futuro, siguiendo la línea de Sarlo en Punto de vista cuando afirmaba que una revista solo podrá significar algo a futuro si está conectada con su presente, con ideas en formación, con ensayos interpretativos: con su carácter experimental. ${ }^{20}$ Lejos de la lectura historiográfica, es el presente lo que constituirá el valor futuro del archivo.

El caso pionero y trunco de $N R$ sirve para pensar en el registro de las mutaciones del mundo en red. Se puede considerar al potencial de archivo como un gesto conservador en sentido clásico a la vez que resiliente frente al imperativo del decir que apabulla todo medio «caliente» de expresión e intervención; se puede pensar a las pulsiones de archivo derrideanas (1997) como doble filo que, por un lado, pueden romper el espesor de la palabra dirigida al por-venir (en vez de destruirse por adelantado, antes incluso de haberse producido, se destruye por la lógica perecedera de la circulación), y por otro quizás poner de relieve el valor atemporal de ciertos documentos que, por esa misma lógica mediática, se encuentran perdidos en la marea informacional.

Si nos cernimos a los formatos digitales de publicación web, el órgano revista hoy encuentra muchos obstáculos frente a la doble posibilidad de: a) intervenir en el presente de los debates, afectar y ser afectada por lo que se dice, se discute y se produce en el entorno que le da origen; 0 b) traducir una coyuntura, sugerir las señas siempre parciales de una estructura de sentimiento, en términos de Williams (1994), reflexiva o analíticamente desde un recorte de la experiencia 
cultural y artística. Esta fue la intención de $N R$ y de las otras revistas digitales pioneras, como EI o LAT: llegar rápido a los lectores para ofrecer una alternativa renovada, otro modo de concebir la crítica cultural y literaria. Sin embargo, la actual estructura de medios, basada en una convergencia estratégica de redes sociales, sitios de periodismo digital y medios audiovisuales para construir temas, problemas y novedades, parece haber fagocitado buena parte del poder de resonancia de los proyectos independientes ${ }^{21}$ en ese encuentro desigual (centralidad de la convergencia versus atomización de espacios que orbitan en la red).

Encuentro como posibilidad teórica y metodológica a explorar el hecho de pensar a las revistas digitales independientes (no solo las desaparecidas como NR, EI o LAT, sino a las que siguen publicando, como Carapachay, Pogo, Paco, Polvo, Luthor, Atletas, Artezeta, Ñusleter, etc.) como órganos independientes de archivo. Esto es, como promesas de futuro, según la definición derrideana, en tanto espacios, refugios y/o herramientas que publican periódicamente, según líneas editoriales precisas o imprecisas, pero para ser leídos en un futuro que desconocemos, por no poder competir con la convergencia digital que centraliza los canales de información. Órganos independientes de archivo que producen para un futuro en el que todo el material de lo que antes fue coyuntura sí pueda pensarse con los tiempos de las rutinas intelectuales, al resguardo del flujo de datos que somete todo discurso y tipo de abordaje a la repercusión efímera o viral.

El órgano revista digital independiente, leído hoy (puede pensarse, también, en los modos actuales de circulación de las revistas impresas), quizás pueda exponer su mayor valía en tanto archivo en progreso, al quedar relegado en términos de resonancia. Como si el método construido para ensayar el nombre de una época necesite, ante todo, que el tiempo pase, y que la dinámica de publicaciones en la web siga reproduciendo el presente expandido, sostenido por la omnipresencia de dispositivos, para así proponer luego un abordaje diferido de la ansiedad por lo nuevo. Una suerte de contrapeso que permita regenerar sentidos atorados por el presente. Esto implica una suerte de contradicción respecto de lo abordado; la misma directora de $N R$, en su primera editorial, definía a una revista como un intento permanente por ganar lectores.

$N R$ construyó su círculo de recepción al compás de las nuevas voces, hasta que la repercusión de su tarea generó las condiciones para contar con aportes regulares de autores consagrados. El vínculo originario con el campo académico definió esta dinámica, conjugado con la crisis y el impulso de alternativas autónomas de expansión, a bajo costo, en la nueva «tierra virtual» que alfabetizó en pocos años a escritores, críticos, académicos, lectores, editores. Un verdadero nuevo intercambio de producción, circulación y debate, tanto virtual como presencial, porque el medio interactivo en el contexto urbano inauguró formas de sociabilidad híbridas, antes desconocidas.

La ironía de considerar a las revistas digitales independientes como órganos que se acerquen más a un dispositivo de construcción de futuro que a una herramienta de intervención en presente es que, durante el siglo XX, esto mismo se asociaba a un «envejecimiento patético», como supo escribir Sarlo (1992). Una revista fuera de actualidad se restringía, para Sarlo, solo a su valor arcaico, desprovisto de su aura esencial (1992). Sin embargo, la inestabilidad de los objetos digitales en red genera finales como el de NR: desaparición e inaccesibilidad, sustantivos salvados a medias por servicios como WayBack Machine que permiten recuperar elementos descontextualizados e incompletos respecto de lo que había sido publicado originalmente en código HTML. Las revistas digitales independientes, más allá de las posibilidades de actualización permanente, pueden entonces alimentar un capital simbólico prometedor como archivos en proceso hasta 
que las condiciones sociotécnicas permitan regenerar cierta resonancia, siempre bajo el riesgo de la misma infraestructura de almacenamiento, codificación y reproducción que suele atentar contra esa misma potencia archivadora.

De aquí se desprende la importancia de establecer políticas de archivo para los objetos digitales en red: importancia de premeditar, frente a la desaparición siempre latente de una publicación periódica, las operaciones necesarias para despojar a los objetos digitales de sus atributos en red. Atributos que fueron creados para que circulen en las redes de información y comunicación, pero que deben aislarse para construir nuevos documentos archivables. Se trataría, entonces, de una compensación de la pérdida de lugar en el presente, y de la merma de valor analítico y expositivo que permite digerir la época (pos)pandémica, para construir elementos capaces de aportar una mirada de época diferida pero con apuesta a la permanencia: una política que se haga cargo, con esa compensación a futuro, de nuestra responsabilidad en la alimentación de un presente expandido, de picoteo, como matriz de consumo y percepción.

Por todo esto, la experiencia $N R$ cicatrizó como paradoja, porque la revista tuvo inscripto en sí su destino de archivo (virtuoso, pensado) mientras hoy está inaccesible a la consulta pública. Las primeras reflexiones de su existencia, frente a las posibilidades interactivas de la web, ponderaban como problema de fondo a la permanencia del material publicado. La revista buscaba iniciar públicamente en la literatura a diversos autores y artistas, como otorgar relieve a diversas problemáticas, para que esos antecedentes obligaran a una apropiación de los materiales por parte de los lectores.

Cuando una revista termina, cuando un diálogo se cierra, es inevitable pensar que algo salió mal. En general, se debe a un cambio de relación del proyecto editorial con el contexto, o a veces a un cambio de contexto de los editores. Hay algo del fracaso de ese «permanecer en el presente» de una publicación que pasa a conformar, de ahí en más, un momento pasado. Una revista que se cierra se vuelve libro. Una suerte de testimonio de algo que ya no es. (Echevarría, 2018; el destacado me corresponde)

Nadie auguraba un presente mediático que se «tragara» al mismo contexto de producción que propició. Hoy una revista que se cierra ni siquiera puede llegar a libro, porque requiere de una temporalidad ajena a la obsolescencia radical de los dispositivos y objetos digitales que se solapan y reemplazan. Cumplida la segunda década del siglo, la apuesta por la permanencia parece depender más de la constitución de una política transversal de archivo que fabrique pasado y futuro a la vez: que aleje a lo que pretende conservar (y poner en valor) de la aplastante condición en red, eso que nos da tanta inmediatez y acceso pero anula las resonancias materiales de la palabra puesta en juego.

\section{Notas}

1 Ver http://revistascientificas.filo.uba.ar/index.php/

matadero/issue/view/263

2 Ver https://revistaseug.ugr.es/index.php/letral/issue/view/536

3 Para profundizar la aparición y desaparición de revistas

digitales en los últimos 15 años ver Vigna $(2015,2020)$.
4 Para Verónica Delgado, por ejemplo, apelar a la forma revista, más allá del soporte y el formato, implica «estudiar las publicaciones como formas privilegiadas de organización o intervención colectiva, que no son equivalentes de las textualidades o escritos que incorporan» (2014:20). 
El taco en la brea \# 14 Papeles de investigación • VIGNA, Breve historización de las revistas digitales de cultura y literatura en Argentina... 20-40

5 Ejemplos en Buenos Aires: grupos de lectura Los Mudos, Carne Argentina, Grupo Alejandría, El Quinteto de la Muerte; actividades literarias periódicas en el Centro Cultural Pachamama; ferias de sellos editoriales independientes en Buenos Aires, Córdoba, La Plata, Rosario, Neuquén, entre otras ciudades; producción de fanzines; editoriales cartoneras como Eloísa (Buenos Aires), Textos de Cartón y Sofía Cartonera (Córdoba), o editoriales de libros de bajo costo como La Creciente (Córdoba).

6 http://linkillo.blogspot.com/

7 De hecho, esto hoy transciende a los soportes. El cambio de siglo acentuó la expansión de estudios sobre publicaciones impresas a partir de dicha apropiación de tecnologías de registro, publicación y archivo. Se multiplicaron los trabajos sobre diarios y revistas de cultura en el ámbito argentino y, aunque no fue algo novedoso, esto consolidó, como afirma Delgado (2014), una convergencia de intereses multidisciplinares y de líneas de investigación. Comenzaron a leerse y archivarse revistas de historia, literatura, arte, filosofía, comunicación, pero sobre todo fue notable la expansión de nociones sociológicas para sistematizar métodos y analizar problemáticas estéticas, políticas e ideológicas (Delgado, 2014).

8 https://archive.org/web/

9 Algunos autores publicados en ese primer período: Pablo Ramos, Juan Pablo Bertazza, Valeria Tentoni, Sonia Budassi, Ricardo Romero, Hernán Vanoli, Félix Bruzzone (los últimos cinco, con experiencias posteriores como autores y editores); Romina Freschi, Diego Grillo Trubba, Juan José Burzi (creador de la revista Los asesinos tímidos).

10 Daniel Link, Elsa Drucaroff, Marcelo Cohen, Jorge Panesi, entre otros.

11 Todas las referencias a Echevarría (2018) que siguen corresponden a esta comunicación personal del 19 de julio.

12 Ver https://web.archive.org/web/20160512130749/http:// no-retornable.com.ar/v4/quienes/
13 Ver https://web.archive.org/web/20080912030811/http:// www.no-retornable.com.ar/v1/quienes/

14 En la presentación: «Si bien en el primer número dijimos que cuando decidimos emprender este proyecto lo primero que tuvimos en claro era que íbamos a ser una revista literaria, nos hemos ido expandiendo hacia otras artes. Ahora, en este número diez, No Retornable se ha transformado en una revista cultural» (ver http://www.no-retornable.com.ar/v1o/quienes/).

15 Ver https://web.archive.org/web/20131019233651/http:// www.no-retornable.com.ar/v14/quienes/

16 Después de la experiencia No Retornable, tanto Echeverría como Nurit Kasztelan, también editora de la revista, fundaron la editorial Excursiones, dedicada al ensayo y otros géneros híbridos.

17 A mediados de 2018, Echevarría recibió un aviso de vencimiento para el pago del servidor/host que alojaba la revista, ya sin actividad. Cuando quiso abonar a través del órgano correspondiente, no lo logró porque alguien había interpuesto un reclamo por el nombre del dominio. Sin asesoramiento legal para poder resolverlo, y frente a la pregunta sobre si seguir abonando una suma importante para mantener a la revista online, debió inclinarse por el no pago y la desaparición de los materiales para la libre consulta (Echevarría, 2018).

$18 \mathrm{Al}$ proyecto editorial Excursiones, Echevarría sumó la apertura de una galería de arte (Acéfala) en la Ciudad de Buenos Aires.

19 https://www.bazaramericano.com/

20 https://web.archive.org/web/20131019233651/

http://www.no-retornable.com.ar/v14/quienes/

21 Hoy pueden nombrarse excepciones como Anfibia, revista de periodismo narrativo que supo construir un conglomerado de ofertas discursivas a partir de sus contenidos (podcasts, talleres de escritura, ediciones impresas a partir de AnfibiaPapel), pero aunque se trata de un medio autónomo cuenta con un asterisco: es un proyecto creado y financiado por la Universidad Nacional de San Martín (otra vez el vínculo con la academia se torna fundamental).

\section{Referencias}

Altamirano, C. y Sarlo, B. (1983). Literatura/Sociedad. Buenos Aires: Hachette.

Artundo, P. (2010). Reflexiones en torno a un nuevo objeto de estudio: las revistas. IX Congreso Argentino de Hispanistas, 27-30 de abril.

Badenes, D. (2016). Dimensiones y preguntas para el análisis de las revistas culturales. En Delgado, V. y Rogers, G. (eds.). Tiempos de papel. Publicaciones periódicas argentinas (siglos XIX-XX) (pp. 344-349). La Plata: UNLP. 
Bernini, E. (2015). Inicios (II). Revista El Matadero, (9), 55-56.

Botto, M. (2006). 1990-2000: la concentración y la polarización de la industria editorial. En De Diego, J.L. (dir.). Editores y políticas editoriales en Argentina (1880-2000) (pp. 209-249). Buenos Aires: Fondo de Cultura Económica.

Botto, M. (2011). Territorios del presente, fronteras de la literatura: pequeñas editoriales y editoriales alternativas. Actas de las 2 da. Jornadas de Intercambios y Reflexiones acerca de la Investigación en Bibliotecología, 27-28 de octubre. FAHCE, Universidad Nacional de La Plata.

Bourdieu, P. (2002). Las reglas del arte. Génesis y estructura del campo literario. Barcelona: Anagrama.

Crespo, R. (Coord.) (2010). Revistas en América Latina: proyectos literarios, políticos y culturales. México: UNAM.

Delgado, V. (2014). Algunas cuestiones críticas y metodológicas en relación con el estudio de revistas. En Delgado, V.; Mailhe, A. y Rogers, G. (coords.). Tramas impresas. Publicaciones periódicas argentinas (siglos $X I X-X X)($ pp. 11-25). La Plata: UNLP.

Derrida, J. (1997). Mal de archivo. Una impresión freudiana. Madrid: Trotta.

Drucaroff, E. (2007). Mercado y literatura. Una relación que molesta. XXI Jornadas de Investigación del Instituto de Literatura Hispanoamericana. Facultad de Filosofía y Letras, Universidad de Buenos Aires.

Echevarría, S. (2009). El futuro llegó, hace rato. No Retornable, (4). http://www.no-retornable.com.ar/v4/ dossier/introduccion.html

Escandell Montiel, D. (2018). El blog en la escritura en español: retrospectiva del hoax literario del comienzo del siglo XXI. Letral, (20), 5-23. https://doi.org/10.30827/rl.voi20.8410

Gilman, C. (1999). Las revistas y los límites de lo decible: cartografía de una época. En Sosnowski, S. (ed.). La cultura de un siglo: América Latina en sus revistas (pp. 461-469). Madrid/Buenos Aires: Alianza.

Gramuglio, M.T. (1983). Sur: constitución del grupo y proyecto cultural. Punto de vista, VI(17), 7-9.

Hernaiz, S. (2012). Revistas literarias y lugar social de la literatura en los años noventa. Rodolfo Walsh no escribió Operación masacrey otros ensayos (pp. 99-127). Buenos Aires: 17 Grises Editora.

Hernaiz, S. (2007, 22 de marzo). Entrevista a Osvaldo Aguirre sobre revistas literarias de los 9o. Archivos de la revista El Interpretador, (32) («noventas»). https://revistaelinterpretador.wordpress.com/2017/03/22/ entrevista-a-osvaldo-aguirre-sobre-revistas-literarias-de-los-noventa/

Isoglio, A. y Vigna, D. (2020). Desafíos teóricos y metodológicos en torno al documento de archivo como objeto digital en la red. Revista Investigación Bibliotecológica, 35(88). En prensa.

Link, D. (2011). Diez años no es nada. Mar Dulce Magazine, (2). http://mardulceeditora.com.ar/magazine/ articulo.php?id=3\&n=1

Montaldo, G. (2017). Ecología crítica contemporánea. Cuadernos de Literatura, 21(41), 50-61. https://doi. org/10.11144/Javeriana.cl21-41.ecco

Olmos, A.C. (2003). Revistas culturales de los ochenta: prácticas críticas como estrategias de intervención. Revista Estudios, (14), 59-67.

Patiño, R. (1997). Intelectuales en Transición. Las revistas culturales argentinas (1981-1987). Cuadernos de Recienvenido, (4), 5-34. http://dlm.fflch.usp.br/sites/dlm.fflch.usp.br/files/recienvenidoo4.pdf

Patiño, R. (2006). Revistas literarias y culturales argentinas de los 80. Ínsula: revistas de letras y ciencias humanas, 715-716. https://www.insula.es/sites/default/files/articulos_muestra/INSULA\%20715-716.htm

Patiño, R. (2008). Revistas literarias y culturales. En Amícola, J. y de Diego, J.L. (eds.). La teoría literaria hoy. Conceptos, enfoques, debates (pp. 154-170). La Plata: Al Margen.

Peller, D. (2015). Mancilla. Revista El Matadero, (9), 105-109.

Pita González, A. y Grillo, M. (2015). Una propuesta de análisis para el estudio de revistas culturales. Revista 
Latinoamericana de Metodología de las Ciencias Sociales, 5(1). http://www.relmecs.fahce.unlp.edu.ar/article/ view/relmecsvo5no1ao6

Pron, P. (2009). La reinvención de lo nuevo: la literatura argentina después de 2001. Revista Quimera, (304), 18-21.

Sarlo, B. (1992). Intelectuales y revistas: razones de una práctica. Cahiers du CRICCAL, (9/10), 9-16. https:// www.persee.fr/doc/ameri_0982-9237_1992_num_9_1_1047

Van Dijck, J. (2016). La cultura de la conectividad. Una historia crítica de las redes sociales. Buenos Aires: Siglo XXI.

Vanoli, H. (2015). Pequeñas editoriales y transformaciones en la cultura literaria Argentina. Apuntes de investigación del CECYP, (15), 161-185.

Vigna, D. (2014). La década posteada. Blogs de escritores argentinos (2002-2012). Córdoba: Alción Editora/CEA.

Vigna, D. (2015). De la tradición de revistas al mundo virtual. Aproximación a las publicaciones culturales digitales en el campo intelectual argentino de la última década. Pilquen (ciencias sociales), (3), 21-35. http://revele.uncoma.edu.ar/htdoc/revele/index.php/Sociales/article/view/1401/pdf.2020

Vigna, D. (2020). La forma revista en su versión digital. Propuesta metodológica para el análisis de publicaciones culturales y literarias desde el contexto argentino. Cuadernos del CILHA, 2O(32), 48-77.

Vilar, M. (2014). Revistas, letras, Luthor. Revista Luthor, (22), 1-8. http://www.revistaluthor.com.ar/pdfs/115.pdf Vilar, M. (2015). No Retornable. Revista El Matadero, (9), 105-126.

Weinberg, L. (2011). Presentación. Cuadernos Americanos, (137) (Dossier Revistas en América Latina), 199-205.

Williams, R. (1994). Sociología de la cultura. Barcelona/Buenos Aires/México: Paidós. 